\title{
Metabolic Syndrome, Abnormal Glucose Tolerance and High Sensitivity- C-Reactive Protein among Women with a History of Gestational Diabetes Mellitus
}

\author{
Sangeetha Shyam ${ }^{1}$, Fatimah Arshad ${ }^{2}$, Rohana Abdul Ghani ${ }^{*}$, Norasyikin A Wahab ${ }^{4}$, Karuthan Chinna ${ }^{5}$, Nik Shanita Safii ${ }^{6}$, Yusof Barakatun \\ Nisak $^{7}$ and Nor Azmi Kamaruddin ${ }^{8}$ \\ ${ }^{1}$ Division of Nutrition and Dietetics, International Medical University, Kuala Lumpur, Malaysia \\ ${ }^{2}$ Department of Nutrition and Dietetics, International Medical University, Kuala Lumpur, Malaysia \\ ${ }^{3}$ Medical Discipline, Faculty of Medicine, Universiti Teknologi MARA, Kuala Lumpur, Malaysia \\ ${ }^{4}$ Endocrine Unit, Department of Medicine, Faculty of Medicine, Universiti Kebangsaan Malaysia (National University of Malaysia), Kuala Lumpur, Malaysia \\ ${ }^{5}$ Epidemiology and Biostatistics Unit, Department of Social and Preventive Medicine, Faculty of Medicine, University of Malaya, Kuala Lumpur, Malaysia \\ ${ }^{6}$ Dietetics Program, School of Healthcare Sciences, Faculty of Health Sciences, Universiti Kebangsaan Malaysia, Kuala Lumpur, Malaysia \\ ${ }^{7}$ Department of Nutrition \& Dietetics, Faculty of Medicine\& Health Sciences, Universiti Putra Malaysia, Serdang, Malaysia \\ ${ }^{8}$ Endocrine Unit, Department of Medicine, Faculty of Medicine, Universiti Kebangsaan Malaysia (National University of Malaysia), Kuala Lumpur, Malaysia
}

\begin{abstract}
Background: Gestational Diabetes Mellitus (GDM) is a risk factor for diabetes and cardiovascular diseases. Early detection of cardio-metabolic risks is recommended for management. This study evaluated the associations between Metabolic Syndrome (MetS), abnormal glucose tolerance and cardiovascular risk factors in Malaysian women with prior GDM.
\end{abstract}

Method: Seventy-seven, non-diabetic women post-GDM, aged 20-40 years (mean BMI: $26.4 \pm 4.6 \mathrm{~kg} / \mathrm{m}^{2}$ ) with high type 2 diabetes risks, were evaluated at a median of four months postpartum. Their anthropometric and biochemical measurements were obtained.

Results: The overall prevalence of MetS and dysglycaemia were $22 \%$ and $29 \%$ respectively. Dysglycaemic was predominantly impaired glucose tolerance (IGT: 77\%).MetS was higher among dysglycaemic subjects although also detected in $13 \%$ of normo glycaemic subjects. Eighty percent of IGT subjects did not have MetS. Sixty-eight percent of subjects had intermediate or high CVD risks (hsCRP>1mg/L). hscRP increased with obesity and was not associated with glycaemic status. Infant birth weight, maternal age and triglycerides were independent predictors of dysglycaemia $(p<0.05)$.

Conclusion: Despite the low prevalence of MetS, elevated levels of hsCRP among these women with priorGDM was highly prevalent. Normoglycaemic subjects with MetS demonstrated intermediate to high risk hsCRP levels. The findings also emphasize the importance of performing OGTT mainly in older post-GDM women, with higher triglycerides and infants who are large for gestational age.

Keywords: Gestational diabetes mellitus; Type 2 diabetes; Metabolic syndrome; Cardiovascular risks; Dysglycaemia; Dyslipidaemia

\section{Introduction}

Gestational Diabetes Mellitus (GDM) which describes abnormal glucose homeostasis in pregnancy, has been recognised to increase maternal risks for the development of diabetes and Cardio-Vascular Diseases (CVD) [1,2]. Previous data has recommended early detection and management of cardio-metabolic risk factors in women post GDM [3]. Central obesity, insulin resistance, glucose intolerance, hypertriglyceridemia, high levels of inflammatory markers and low high density lipoprotein cholesterol (HDL-C) are components of metabolic syndrome (MetS) and commonly seen in women with previous GDM $[4,5]$. MetS predicts approximately $50 \%$ of the risk for diabetes and $25 \%$ of all new-onset CVD [6]. Hence a diagnosis of MetS in women postGDM identifies women with increased cardio-metabolic risks who would benefit from early intervention [7].

High sensitivity C-reactive protein (hs-CRP) is an inflammatory marker recommended for risk stratification for individuals with high cardiovascular risk $[8,9]$. MetS is associated with high levels of hsCRP and linked to increased risk for CVD and diabetes [10,11].This study evaluated the associations between MetS, abnormal glucose tolerance and cardiovascular risk factors in Malaysian women with prior GDM. Currently, there is a paucity of similar data for the Malaysian population.

\section{Materials and Methods}

This project was approved by the Ethics and Research Review Committees of the institutions involved consistent with the national regulations. Subjects who were diagnosed to have had GDM (WHO criteria [12]) were identified 2-6 months after delivery. The inclusion criteria were women between the ages of 20-40 years with the presence of at-least one of the following three risk factors: 1.central obesity [described as a body mass index (BMI) $>23 \mathrm{~kg} / \mathrm{m}^{2}$, or waist circumference $(\mathrm{WC})>80 \mathrm{~cm}$ ], 2. Dysglycaemia (Impaired glucose tolerance (IGT: $2-\mathrm{h}$ plasma glucose $\geq 7.8$ and $<11.1 \mathrm{mmol} / \mathrm{L}$ [13]) and/

*Corresponding author: Rohana Abdul Ghani, MMed, Medical Discipline, Faculty of Medicine,Universiti Teknologi MARA, Kuala Lumpur, Malaysia, Tel: +60125177326; E-mail:agrohana@gmail.com

Received July 22, 2014; Accepted August 25, 2014; Published September 01, 2014

Citation: Shyam S, Arshad F, Ghani RA, Wahab NA, Chinna K, et al. (2014) Metabolic Syndrome, Abnormal Glucose Tolerance and High SensitivityC-Reactive Protein among Women with a History of Gestational Diabetes Mellitus. J Diabetes Metab 5: 424 doi:10.4172/2155-6156.1000424

Copyright: ( 2014 Shyam S, et al. This is an open-access article distributed under the terms of the Creative Commons Attribution License, which permits unrestricted use, distribution, and reproduction in any medium, provided the original author and source are credited. 
or Impaired fasting glucose (IFG: FBS $\geq 5.6$ to $<7.0 \mathrm{mmol} / \mathrm{L}$ [6]) values at the screening Oral Glucose Tolerance Test (OGTT) and presence of family history of diabetes. Exclusion criteria were: Subjects with type 2 diabetes (as defined by American Diabetes Association, 2007 [13]), pregnancy, and the use of drugs which may affect metabolic profiles were excluded. A total of 304 women with GDM identified from the Hospital Delivery Register were screened. Seventy-seven subjects were eligible and informed consent was obtained. All outcome measures were measured postpartum.

Subjects' body weight and height, rounded to $0.1 \mathrm{~kg}$ and $0.1 \mathrm{~cm}$ respectively, were measured in light clothing, without footwear and after emptying pockets. Body weight was measured using digital weighing scales (Model: BWB-800A, Tanita Corporation, Tokyo, Japan) and height using the wall-mounted stadiometer (Model No.: 206, SECA, Hamburg, Germany) and BMI was calculated. Waist (WC) and hip circumference were measured following WHO guidelines and Waist-Hip Ratio (WHR) was calculated [14]. Body fat \% and trunk fat $\%$ were measured using the dual-emission X-ray absorptiometry (DEXA, Model: Delphi, Hologic Systems, Bedford, USA) as per the manufacturer's instructions.

Blood Pressure (BP) was taken in the sitting position from the left arm after a 10-minute rest, using the automatic sphygmomanometer (Colin Press Mate, Colin Medical Technology Corporation, Tokyo, Japan). An average of two consecutive readings was measured [15].

Blood samples were obtained after a 10-hour overnight fast. OGTT was performed using $75 \mathrm{~g}$ of dextrous anhydrous glucose dissolved in $250-300 \mathrm{ml}$ of drinking water. Blood samples were collected pretest and at two hours (2HPP). Blood glucose was measured using the Hexokinase/G6PD method. Triglyceride (TG) and Total Cholesterol (TC) were measured using enzymatic colorimetric method. HDLcholesterol was assessed by homogeneous enzymatic colorimetric method. LDL-cholesterol was calculated using the Friedwalds's formula. Serum samples for hs-CRP testing were stored at $-20^{\circ} \mathrm{C}$ degrees until assayed using enzymatic system. hsCRP Values above $10 \mathrm{mg} / \mathrm{L}$ were excluded to avoid possibility of ongoing infection [16].

\section{Definition of cardio-metabolic risks}

A combination of $\mathrm{WC}>80 \mathrm{~cm}, \mathrm{BMI}>23$ and body fat $>35 \%$ indicate obesity with an increased risk for cardio-metabolic diseases [17]. The IDF harmonized criteria was used to define MetS [6]; i.e. presence of any three out of the following five components: 1 . the presence of central obesity (for South Asian women WC $\geq 80 \mathrm{~cm}$, or BMI is $>30 \mathrm{~kg} /$ $\left.\mathrm{m}^{2}\right)$ 2. raised $\mathrm{TG} \geq 150 \mathrm{mg} / \mathrm{dl}(1.7 \mathrm{mmol} / \mathrm{L}) 3$. reduced HDL cholesterol abnormality $<50 \mathrm{mg} / \mathrm{dl}(1.29 \mathrm{mmol} / \mathrm{L})$ in females, 4.raised BP systolic $\mathrm{BP} \geq 130$ or diastolic $\mathrm{BP} \geq 85 \mathrm{mmHg}$ and 5 . raised fasting blood sugar (FBS) $\geq 100 \mathrm{mg} / \mathrm{dl}(5.6 \mathrm{mmol} / \mathrm{L})$. HsCRP values were used to stratify CVD risk into three categories: "Low" (hsCRP $<1 \mathrm{mg} / \mathrm{L}$ ), "Intermediate" (1-3 mg/L) amd "High" (>3 mg/L)[16].

\section{Statistical analyses}

Statistical analyses were performed using IBM SPSS (Version 19, Somers, NY). Normally distributed data are presented as mean SD. Median and Inter-Quartile Ranges (IQR) are presented for data that was not normally distributed. Differences between groups for continuous data were assessed by independent $t$-test (for normally distributed data) and nonparametric tests for data not normally distributed. Chi-square was used to analyse categorical data. Associations between variables were studied with Pearson's or Spearman's correlation co-efficient depending on the normality of the data. The statistical significance standard was set at $5 \%$.
To investigate associations with dysglycaemia, variables were entered into a logistic regression model with presence or absence of dysglycaemia as the dependant variables. Age, number of children, number of pregnancies, birth weight of children, WHR and TG were the co-variates used in the model. Variables not substantially contributing to the model were systematically removed in a backward stepwise regression process using the likelihood ratio test as the criterion for removal. Age, baby birth weight and TG remained the significant predictors in the final model. The Hosmer-Lemeshow $\chi 2$ test was used to assess the goodness of fit between the observed and predicted number of outcomes for the final model and $p>0.05$ was taken to indicate a good fit. The final model for predicting dysglycaemia had a good fit (HosmerLemeshow $\chi 2$ test $\mathrm{p}$ value $=0.814$ ) .

\section{Results}

The demographic and metabolic parameters are shown in Table 1. The median duration since last GDM delivery to the time of screening was 4 months (IQR 2)The majority (74\%) of the subjects were Malays, followed by Chinese (17\%), Indians (6\%) and others (3\%, including one Indonesian and one Myanmarese).

The mean BMI, body fat $\%$ and WC of the subjects were above recommended healthy limits for Asian women [17]. Overall, 17 subjects (22\%) met the IDF harmonized criteria for MetS [6]. Based on the criteria, $67.5 \%$ of subjects had central obesity, $11.7 \%$ had IFG (FBS $>5.6$ $\mathrm{mmol} / \mathrm{L}$ ), $12 \%$ had $\mathrm{TG}>1.7 \mathrm{mmol} / \mathrm{L}$, while $36 \%$ had $\mathrm{HDL}-\mathrm{C}<1.3$ $\mathrm{mmol} / \mathrm{L}$, and $24 \%$ had elevated BP [6]. Based on hsCRP CV risk stratification, 20 subjects $(31.7 \%)$ were in the low risk, $25(39.7 \%)$ in the intermediate risk and $18(28.6 \%)$ were in the high risk category [16].

Women with or without MetS, were similar in their ages $(31.2 \pm 4.7$ vs. $31.8 \pm 3.2$ years, $\mathrm{p}=0.647$, Figure 1 ) and family history of diabetes ( 82.4 vs. $83.1 \%, p=1.0$ ) There were no differences in the total number of pregnancies, number of GDM pregnancies, number of parity, time lapse since last GDM-delivery and birth-weight of infants. However, women with MetS had earlier diagnosis of GDM during pregnancy at median of 17 (IQR 8.5) vs. 26 (8.5) weeks, $\mathrm{p}=0.002$. The subjects who satisfied the MetS criteria had higher BMI, body and trunk fat and higher systolic and diastolic BP ( $<<0.05$, Table 2$)$.

Among the 77 subjects, 22 (29\%) demonstrated dysglycaemia

\begin{tabular}{|l|c|}
\hline Parameter & Mean SD \\
\hline Age $(\mathrm{y})$ & $30.5 \pm 9$ \\
\hline Weight $(\mathrm{Kg})$ & $65.1 \pm 12.1$ \\
\hline BMI $\left(\mathrm{Kg} / \mathrm{m}^{2}\right)$ & $26.4 \pm 4.6$ \\
\hline Waist Circumference (cm.) & $83.2 \pm 8.8$ \\
\hline Waist-Hip- Ratio & $0.81 \pm 0.05$ \\
\hline Body Fat \% & $38.4 \pm 5.3$ \\
\hline Trunk fat \% & $37.2 \pm 6.6$ \\
\hline Fasting Blood Glucose (mmol/L) $\dagger$ & $4.7 \pm 0.7$ \\
\hline 2h- postprandial blood glucose (mmol/L) & $6.51 \pm 1.6$ \\
\hline Triglyceride (mmol/L)† & $0.86 \pm 0.72$ \\
\hline Total Cholesterol (mmol/L) & $5.18 \pm 0.32$ \\
\hline HDL-Cholesterol (mmol/L) $\dagger$ & $1.43 \pm 0.43$ \\
\hline LDL-Cholesterol (mmol/L) & $3.30 \pm 0.79$ \\
\hline Systolic BP (mmHg) $\dagger$ & $115.5 \pm 21$ \\
\hline Diastolic BP (mmHg) & $67.4 \pm 11.7$ \\
\hline
\end{tabular}

GDM: Gestational diabetes mellitus; BP- Blood pressure;†: values not normally distributed, data presented as median (Interquartile Range (IQR))

Table 1: Demographic and Metabolic Parameters in Post-GDM Subjects without Diabetes. 


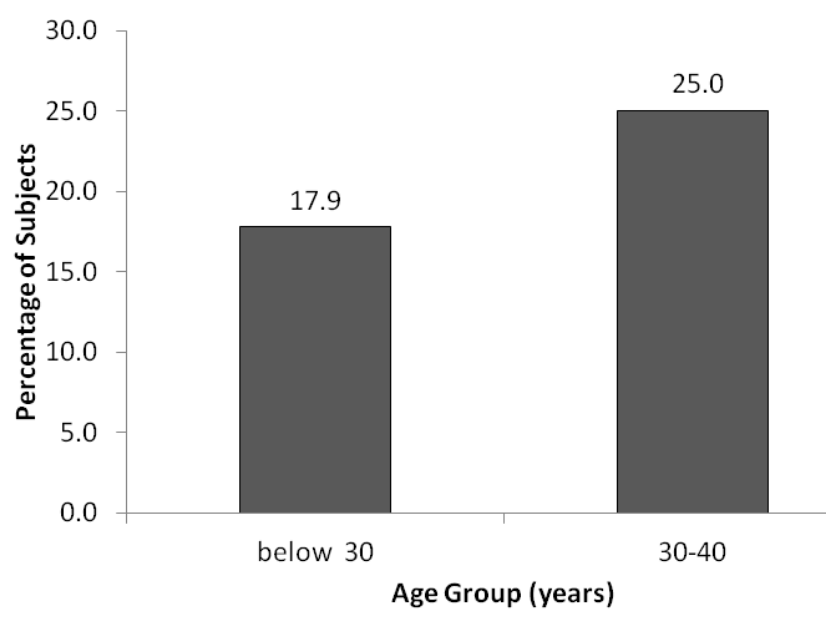

Figure 1: Age and Prevalence of Metabolic Syndrome.

\begin{tabular}{|l|c|c|c|}
\hline \multirow{2}{*}{ Parameter } & \multicolumn{2}{|c|}{ Metabolic Syndrome } & $P^{1}$ value \\
\cline { 2 - 4 } & Yes $(\mathrm{n}=17)$ & No $(\mathrm{n}=60)$ & \\
\hline Weight $(\mathrm{kg})$ & $74.0 \pm 11.7$ & $62.6 \pm 11.0$ & $<0.001$ \\
\hline BMI $\left(\mathrm{Kg} / \mathrm{m}^{2}\right)$ & $29.8 \pm 4.2$ & $25.5 \pm 4.3$ & $<0.001$ \\
\hline WC $(\mathrm{cm})$ & $90.5 \pm 8.4$ & $81.1 \pm 7.8$ & $<0.001$ \\
\hline WHR & $0.84 \pm 0.05$ & $0.80 \pm 0.05$ & 0.009 \\
\hline Body Fat \% & $41.5 \pm 4.3$ & $37.6 \pm 5.3$ & 0.009 \\
\hline Trunk fat \% & $42.3 \pm 4.7$ & $35.7 \pm 6.4$ & $<0.001$ \\
\hline FBS $(\mathrm{mmol} / \mathrm{L}) \dagger$ & $5.4 \pm 0.47$ & $4.6 \pm 0.41$ & $<0.001$ \\
\hline 2HPP(mmol/L) & $7.4 \pm 1.6$ & $6.3 \pm 1.4$ & 0.005 \\
\hline TC $(\mathrm{mmol} / \mathrm{L})$ & $5.2(1.5)$ & $5.0(1.09)$ & 0.418 \\
\hline TG $(\mathrm{mmol} / \mathrm{L}) \dagger$ & $1.8(0.8)$ & $0.76(0.37)$ & $<0.001$ \\
\hline HDL $(\mathrm{mmol} / \mathrm{L}) \dagger$ & $1.0(0.16)$ & $1.5(0.23)$ & $<0.001$ \\
\hline LDL $(\mathrm{mmol} / \mathrm{L})$ & $3.2(1.28)$ & $3.2(0.96)$ & 0.418 \\
\hline TC:HDL $\dagger$ & $5.2(1.5)$ & $3.3(1.4)$ & $<0.001$ \\
\hline HDL:LDL $\dagger$ & $0.3(0.1)$ & $0.48(0.2)$ & 0.001 \\
\hline Systolic BP $(\mathrm{mmHg}) \dagger$ & $126 \pm 17.4$ & $116.9 \pm 14.1$ & 0.030 \\
\hline Diastolic BP $(\mathrm{mmHg})$ & $72.6 \pm 12.1$ & $65.9 \pm 11.3$ & 0.036 \\
\hline hsCRP & $3.07 \pm 2.1$ & $2.09 \pm 1.8$ & 0.111 \\
\hline Ab & & & \\
\hline
\end{tabular}

Abbreviations: GDM: Gestational diabetes mellitus; MetS: Metabolic syndrome BMI: Body mass Index; WC: Waist Circumference; WHR: Waist Hip ratio; FBS Fasting blood glucose; 2HPP: 2 hour post prandial blood glucose on $75 \mathrm{~g}$ OGTT; TC: Total cholesterol; TG- Triglyceride; BP: Blood pressure; BBW: Baby birth weight Values are presented as mean $\pm S D, \dagger$ if not normally distributed, data presented as median (interquartile range (IQR)),

$\mathrm{P}^{1}$-comparing values across those with and without metabolic syndrome

Table 2: Comparison of Anthropometric and Metabolic Parameters of Post-GDM subjects with or without Metabolic Syndrome.

(IFG or IGT or both) and 55 (71\%) had normoglycaemia. Within the dysglycaemic group, five had IFG only, 13 had IGT only and four subjects had both abnormalities. The demographic and metabolic parameters of the two groups are shown in Table 3. Subjects with dysglycaemia were significantly older $(33.9 \pm 3.9$ vs. $30.3 \pm 4.2$ years, $\mathrm{p}=0.003)$, reported a higher number of pregnancies (mean (SD) 2.7(1.3) vs. 2.0(1.4), $\mathrm{p}=0.025$ ) and had more children (mean (SD) 2.4(1) vs. 1.97(1.2), $\mathrm{p}=0.028)$ compared to those with normoglycaemia (Refer Table 3 ). Subjects with dysglycaemia had significantly higher WHR $(0.83 \pm 0.05$ vs. $0.80 \pm 0.05, \mathrm{p}=0.037$ ) and TG levels (median (IQR): $1.3(1.02)$ vs. $0.72(0.26), \mathrm{p}=0.005)$ compared to those with normoglycaemia (Table 3 ). The dysglycaemic group had more subjects with high TG $>1.7 \mathrm{mmol} / \mathrm{L}$
( $24 \%$ vs. $7 \%, \mathrm{p}=0.105)$ and low $\mathrm{HDL}-\mathrm{C}<1.29 \mathrm{mmol} / \mathrm{L}$ (52\% vs. $29 \%$, $\mathrm{p}=0.067)$. The dysglycaemic group demonstrated a higher prevalence of MetS in comparison to the normoglycaemic group (48\% vs. $13 \%$, $\mathrm{p}=0.001$ ). All subjects who had both IFG and IGT met the criteria for MetS, in comparison to $80 \%$ of those with only IGT and $15.4 \%$ of those with only IFG (Figure 2). The dysglycaemia group had more MetS

\begin{tabular}{|c|c|c|c|}
\hline Parameter & $\begin{array}{l}\text { Normoglycaemia } \\
\quad(n=55)\end{array}$ & $\begin{array}{l}\text { Dysglycaemia } \\
\quad(n=22)\end{array}$ & $\mathbf{P}^{1}$ \\
\hline Age $(y) \dagger$ & $30.3 \pm 4.2$ & $33.9 \pm 3.9$ & 0.001 \\
\hline No. of Pregnancies & $2.7(1.3)$ & $2.0(1.4)$ & 0.025 \\
\hline No. GDM Pregnancies † & $1.00(0)$ & $1(1)$ & 0.066 \\
\hline Parity & $2.4(1)$ & $1.97(1.2)$ & 0.028 \\
\hline $\begin{array}{l}\text { GDM identified (month of } \\
\text { pregnancy) } †\end{array}$ & $6.0(2)$ & $4.5(3)$ & 0.277 \\
\hline Baby birth weight (kg) & $3.1 \pm 0.38$ & $3.3 \pm 0.43$ & 0.022 \\
\hline Weight (kg) & $63.6 \pm 11.8$ & $68.9 \pm 12.2$ & 0.083 \\
\hline $\mathrm{BMI}\left(\mathrm{kg} / \mathrm{m}^{2}\right)$ & $25.9 \pm 4.6$ & $27.8 \pm 4.5$ & 0.108 \\
\hline WC (cm) & $81.9 \pm 1.2$ & $86.5 \pm 1.7$ & 0.037 \\
\hline WHR & $0.80 \pm 0.05$ & $0.83 \pm 0.05$ & 0.037 \\
\hline Body Fat \% & $38.2 \pm 5.6$ & $39.0 \pm 4.7$ & 0.592 \\
\hline Trunk fat $\%$ & $36.6 \pm 6.9$ & $38.8 \pm 5.7$ & 0.213 \\
\hline $\mathrm{FBS}(\mathrm{mmol} / \mathrm{L}) \dagger$ & $4.6 \pm 0.41$ & $5.2 \pm 0.52$ & 0.0001 \\
\hline 2HPP (mmol/L) & $5.87 \pm 1.1$ & $8.1 \pm 1.4$ & $<.0001$ \\
\hline $\mathrm{TG}(\mathrm{mmol} / \mathrm{L}) \dagger$ & $0.72(0.26)$ & $1.3(1.02)$ & 0.005 \\
\hline $\mathrm{TC}(\mathrm{mmol} / \mathrm{L})$ & $5.2(0.79)$ & $5.1(0.95)$ & 0.794 \\
\hline $\mathrm{HDL} \_\mathrm{C}(\mathrm{mmol} / \mathrm{L}) \dagger$ & $1.4(0.22)$ & $1.2(0.67)$ & 0.146 \\
\hline LDL-C (mmol/L) & $3.3 \pm 0.76$ & $3.3 \pm 0.88$ & 0.832 \\
\hline $\mathrm{TC} / \mathrm{HDL} \dagger$ & $3.7 \pm 1.11$ & $4.24 \pm 1.02$ & 0.082 \\
\hline HDL/LDL † & $0.48(0.2)$ & $0.36(0.2)$ & 0.133 \\
\hline Systolic BP $(\mathrm{mmHg}) \dagger$ & $117 \pm 14.7$ & $123.8 \pm 16.1$ & 0.077 \\
\hline Diastolic BP (mmHg) & $66.2 \pm 11.6$ & $70.1 \pm 11.8$ & 0.120 \\
\hline $\mathrm{hsCRP}(\mathrm{mg} / \mathrm{L})$ & $2.0 \pm 2.38$ & $1.24 \pm 2.48$ & 0.844 \\
\hline
\end{tabular}

Abbreviations: GDM: Gestational Diabetes Mellitus; BMI: Body mass Index WC: Waist Circumference; HC: Hip circumference; WHR- waist Hip ratio; FBS Fasting blood sugar; 2HPP: 2 hour post prandial blood glucose on OGTT test TG: Triglyceride; TC: Total cholesterol; BP: Blood pressure; $\mathrm{P}^{1}$-comparing values across normal and abnormal glucose tolerance (IFG, IGT, and IFG+IGT), values are presented as mean $\pm S D$, $\dagger$ - if not normally distributed, data presented as median (Interquartile Range (IQR))

Table 3: Demographics and Metabolic Parameters of Subjects Post-GDM with Normoglycaemia and Dysglycaemia.

\section{Metabolic Syndrome and Glycemic Status of Subjects}

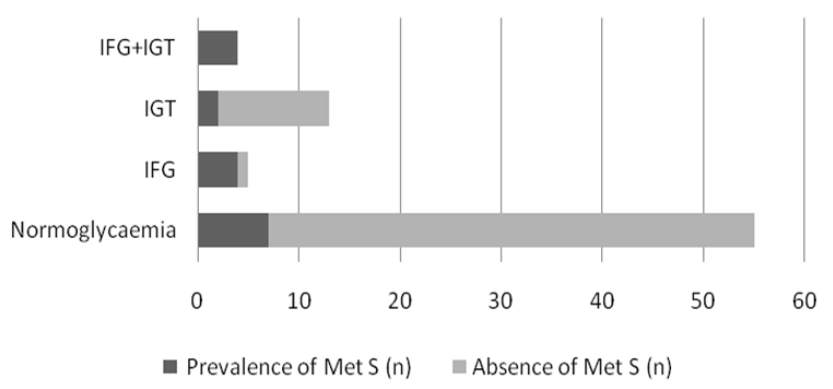

Figure 2: Prevalence of Metabolic Syndrome and Dysglycaemia.

Legend: MetS- Presence of Metabolic Syndrome, No MetS- absence of Metabolic Syndrome, IFG: Impaired Fasting Glucose Only, IGT: Impaired Glucose Tolerance Only, IFG+IGT: Presence of IFG and IGT. Prevalence presented in count. 
Citation: Shyam S, Arshad F, Ghani RA, Wahab NA, Chinna K, et al. (2014) Metabolic Syndrome, Abnormal Glucose Tolerance and High SensitivityC-Reactive Protein among Women with a History of Gestational Diabetes Mellitus. J Diabetes Metab 5: 424 doi:10.4172/2155-6156.1000424

Page 4 of 6

criterion compared to the normoglycaemic group (median: 3 (IQR 2) vs. $1(\mathrm{IQR} 2), \mathrm{p}=0.006)$

Logistic regression analysis showed that infant birth weight, TG and age were significant independent predictors of postpartum dysglycaemia among this post-GDM cohort (OR: 8.723, $\mathrm{p}=0.018$; OR= 5.56, $\mathrm{p}=0.008$; and $\mathrm{OR}=1.29, \mathrm{p}=0.002$, respectively).

Among subjects diagnosed with MetS, 18.2, 36.4 and $45.5 \%$ of subjects were in the low, intermediate and high hsCRP risk strata. Among subjects without Met S, 34.6, 40.4 and 25\% of the subjects were in the low, intermediate and high hsCRP risk strata. There was no significant trend associating presence of Met $S$ with higher hsCRP levels $(p=0.343)$. hscRP levels did not vary significantly between

\begin{tabular}{|c|c|c|}
\hline $\begin{array}{c}\text { No. of MetS criteria } \\
\text { satisfied }^{*}\end{array}$ & $\begin{array}{c}\text { Dysglycaemia } \\
\text { \% of subjects }\end{array}$ & $\begin{array}{c}\text { Normoglycaemia } \\
\text { \% of subjects }\end{array}$ \\
\hline 0 & 14.2 & 36.4 \\
\hline 1 & 14.2 & 27.3 \\
\hline 2 & 24.8 & 23.6 \\
\hline 3 & 38.1 & 12.7 \\
\hline 4 & 9.5 & 0 \\
\hline
\end{tabular}

* Difference in distribution between groups $p<0.001$

Table 4: Metabolic Syndrome criteria in post-GDM women with and without dysglycaemia.

\begin{tabular}{|l|c|c|c|c|}
\hline & \multicolumn{3}{|c|}{ hsCRP CV risk categories } & \\
\hline & Low & Intermediate & High & p Value \\
\hline Weight $(\mathrm{kg})$ & $53.6(10)$ & $65.8(13)$ & $68.5(16)$ & $<0.001$ \\
\hline BMI & $21.6(4.6)$ & $26.3(4.7)$ & $28.2(6.3)$ & $<0.001$ \\
\hline WC cm & $77 \pm 6.7$ & $82.5 \pm 6.9$ & $86.6 \pm 5.3$ & $<0.001$ \\
\hline Body Fat \% & $33 \pm 5.1$ & $37.7 \pm 6.2$ & $41.7 \pm 3.8$ & $<0.001$ \\
\hline Trunk fat \% & $30.1 \pm 6.5$ & $36.5 \pm 4.4$ & $40.8 \pm 3.4$ & $<0.001$ \\
\hline TC & $5.3 \pm 0.9$ & $4.9 \pm 0.8$ & $5.0 \pm 0.87$ & 0.04 \\
\hline HDL & $1.5(0.32)$ & $1.37(0.27)$ & $1.38(0.38)$ & 0.035 \\
\hline No. of MetS Components & $0(1.5)$ & $1(2)$ & $2(1.5)$ & 0.002 \\
\hline
\end{tabular}

Abbreviations: GDM: Gestational Diabetes Mellitus; BMI: Body mass Index; WC: Waist Circumference: TC: Total cholesterol, $\mathrm{P}^{1}$ : comparing values across the hsCRP risk categories, values are presented as mean $\pm S D$, $\dagger$ - if not normally distributed, data presented as median (interquartile range (IQR))

Table 5: HighsensitivityC-reactive protein (hsCRP) based risk and metabolic outcomes of interest.

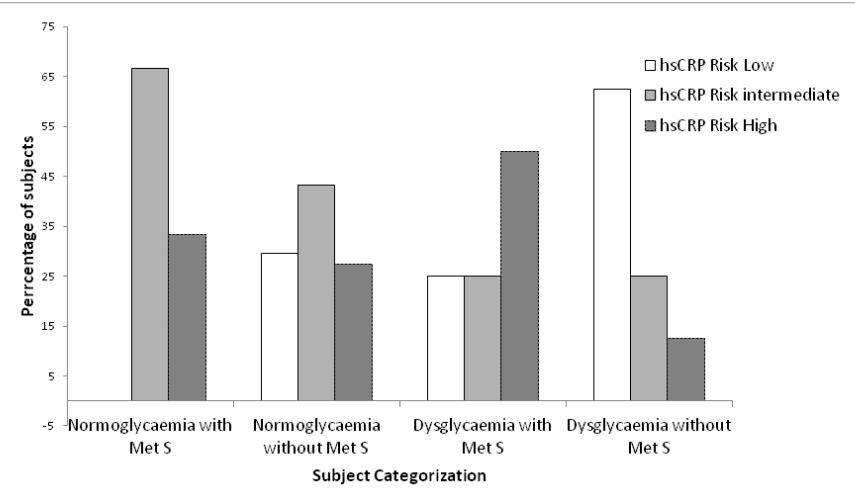

Figure 3: hsCRP Risk Stratification and Presence of Dysglycaemia and Met $\mathrm{S}$ among Post-GDM Women.

Legend: MetS- Metabolic Syndrome, hsCRP: high sensitivity C - reactive protein. HsCRP values based CVD risk startification: "Low" (hsCRP $<1 \mathrm{mg} / \mathrm{L}$ ), "Intermediate" (1-3mg/L) amd "High" (>3mg/L) [16].

\begin{tabular}{|l|c|c|}
\hline Correlation with time of GDM diagnosis \\
\hline Parameter & $r^{*}$ & P value \\
\hline Weight & -0.246 & 0.037 \\
\hline WC & -0.295 & 0.012 \\
\hline Hip & -0.274 & 0.020 \\
\hline BMI & -0.307 & 0.009 \\
\hline Total Body Fat\% & -0.259 & 0.034 \\
\hline Trunk Fat\% & -0.310 & 0.010 \\
\hline FBS & -0.238 & 0.044 \\
\hline 2HPP & -0.29 & 0.013 \\
\hline TG & -0.374 & 0.001 \\
\hline Systolic BP & -0.287 & 0.015 \\
\hline Diastolic BP & -0.301 & 0.011 \\
\hline HDL-C & 0.318 & 0.007 \\
\hline TC: HDL & -0.30 & 0.009 \\
\hline LDL:HDL & -0.287 & 0.015 \\
\hline MetS Diagnosis & -0.367 & 0.002 \\
\hline Presence of Dysglycaemia & -0.129 & 0.280 \\
\hline Total no. of Metabolic Risks & -0.468 & $<0.001$ \\
\hline hsCRP & 0.202 & 0.112 \\
\hline
\end{tabular}

$r$ *- Spearman's correlation coefficient

Abbreviations: WC: Waist Circumference; BMI: Body mass Index; FBS: Fasting blood sugar; 2HPP: 2 hour post prandial blood glucose on $75 \mathrm{~g}$ OGTT test; TG: Triglyceride; TC: Total cholesterol; BP: Blood pressure; MetS: Metabolic Syndrome Table 6: Association between Time of GDM Diagnosis during Pregnancy and Postpartum Metabolic Parameters.

subjects with and without MetS $(3.07 \pm 2.1$ vs. $2.09 \pm 1.8 \mathrm{mg} / \mathrm{L}$, $\mathrm{p}=0.111$, Table 2).

Subjects in the high hsCRP category $>3 \mathrm{mg} / \mathrm{L}$ were significantly heavier, had increased WC, body and trunk fat with lower HDL-C levels (Table 5). Regression analysis showed that for every $5 \%$ increase in total body fat, there was an increase of hsCRP by $1.05 \mathrm{mg} / \mathrm{L}$.

The mean FBS in subjects in the low, intermediate and high hsCRP risk categories were similar $(4.7 \pm 0.5,4.5 \pm 0.5$ and $4.8 \pm 0.6$ $\mathrm{mmol} / \mathrm{L}$, respectively $\mathrm{p}=0.785)$. The $2 \mathrm{HPP}$ in these hsCRP risk strata also showed no significant difference $(6.7 \pm 1.8,6.1 \pm 1.7$ and $7.0 \pm 1.3$ $\mathrm{mmol} / \mathrm{L}$, respectively, $\mathrm{p}=0.165)$. Median hsCRP levels were comparable between subjects with and without dysglycaemia (median 1.7 (IQR 3.5) vs. $1.5(\mathrm{IQR} 2.5) \mathrm{mg} / \mathrm{L}, \mathrm{p}=0.844)$.

The percentage of subjects within the different hsCRP categories, glucose tolerance and Met $S$ status are illustrated in Figure 3. The group with MetS and dysglycaemia revealed the highest percentage of subjects within the high risk hsCRP category. However, subjects with normoglycaemia but who met sufficient criteria for MetS were all within the intermediate and high hsCRP CV risk categories. Furthermore approximately $70 \%$ of the normoglycaemic subjects without MetS were in intermediate and high hsCRP CV risk categories.

The time of GDM diagnosis during pregnancy showed small but significant negative correlation with postpartum anthropometric measures, glycaemic variables, TG, BP and MetS diagnosis (Table 6). Overall, $82 \%$ of the subjects had a family history of diabetes. Subjects with family history of diabetes had higher TC (median 5.18 vs. 4.89 $\mathrm{mmol} / \mathrm{L}, \mathrm{p}=0.019$ ), TC: HDL ratio (median 3.82 vs. $3.29, \mathrm{p}=0.043$ ) and LDL- cholesterol (mean 3.39 vs. $2.86 \mathrm{mmol} / \mathrm{L}, \mathrm{p}=0.027$ ) levels. Both the dysglycaemic and the normoglycaemic groups had similar prevalence of family history of diabetes ( 78.2 vs. $90.9 \%, \mathrm{p}=0.325$ ) 


\section{Discussion}

This study demonstrated a prevalence of MetS at $22 \%$ among highrisk Post-GDM women at a median postpartum duration of 4 months. The prevalence was comparable to the $20 \%$ MetS prevalence reported among Canadian GDM women at three months postpartum [7]. The IDF harmonized criteria which included the presence of central obesity as one of the five criterions to diagnose MetS was used in this study. To validate the use of this criterion in early postpartum, when there may be some retention of weight gained during the pregnancy [18], we performed a sensitivity analysis which was similar to the approach documented in an earlier study conducted among Canadian Post-GDM women at 3-months postpartum [7]. The sensitivity analysis excluded the criterion for central obesity and defined MetS by the presence of two of the four other MetS components. The results of sensitivity analysis indicate that MetS diagnosis in the early postpartum period (2-6months postpartum) is not affected by post-delivery weight retention and after this adjustment, the prevalence of $22 \%$ remained unaltered. However, larger cross-sectional studies are needed to confirm the validity of using MetS criteria in early postpartum.

Despite the concern on residual postpartum weight and waist circumference and by the inclusion criterion of this study including high-risk subjects, our observation was notably low in comparison to previously reported 2-3 fold increase in MetS prevalence among post GDM-women as compared to those with normal pregnancies $[7,19,20]$. The $22 \%$ MetS prevalence in our study group was similar to the figure reported in a population of healthy women in the North-Eastern part of the country (24\%). This relatively high prevalence within the latter cohort may partly be due to the inclusion of older women as the age range was noticeably wider (30-57 years old) [20]. Furthermore, the national estimate of MetS among adult females, which include a wider age range of between 18-70 years of age, for the country is $33.1 \%$ [21].

All subjects with both IFG and IGT met the criteria for MetS and almost half of those with either IFG or IGT had the same diagnosis. However, within the normoglycaemic group, $13 \%$ of the subjects were found to have MetS which was predominantly contributed by low HDL levels $(n=7)$, hypertriglyceridemia $(n=4)$ and elevated BP $(n=3)$. These findings suggest an added role of diagnosing MetS normoglycaemic women as it identified increased cardiovascular risks in a sub-group that would otherwise be overlooked due to their younger age and normoglycaemic status. This is further supported by the hsCRP levels, which indicate that despite being normoglycaemic all subjects who had MetS were within the intermediate and high risk categories.

Subjects with dysglycaemia had an expected higher prevalence of MetS in comparison to those with normoglycaemia ( $48 \%$ vs. $13 \%$, $\mathrm{p}=0.001$ ). However, dysglycaemic subjects who did not have MetS seemed to be predominantly those with IGT only $(n=11 / 13)$ (Figure 2). This observation could be largely attributed to the MetS diagnostic criteria which utilises IFG to qualify glucose intolerance rather than IGT, the latter being the more commonly detected in GDM [3]. This is proven within the study cohort, which showed prevalence of IGT being almost three times more common than IFG. These observations may suggest the importance of performing OGTT postpartum to evaluate postprandial dysglycaemia in the absence of IFG in post GDM women. A Met S diagnosis using the fasting glucose levels may not satisfactorily capture the prevalent abnormal glucose tolerance among women post-GDM.

Our data demonstrated an increase in the prevalence of dysglycaemia with age, which is consistent with a Canadian post-GDM cohort [22]. The increased prevalence of dysglycaemia among older subjects can be expected as insulin resistance increases with age [23]. Logistic regression analyses found that for every one year increase in maternal age among the study subjects there was an associated 25\% higher risk for developing postpartum dysglycaemia. Maternal postpartum dysglycaemia was also significantly associated with higher infant birth weight. Logistic regression analysis showed that infant's birth weight was a significant independent predictor of postpartum dysglycaemia in the mother. This finding reaffirms earlier studies which demonstrated Asian women who gave birth to infants with heavier birth weight are more likely to develop insulin resistance [24]. Therefore, our data emphasized the importance of evaluating postpartum dysglycaemia among older women with GDM and those with heavier infants [22].

Insulin resistance, higher body weight, WC and body fat are associated with higher hsCRP levels which is further linked to increased inflammatory state [16]. Hence, it was not surprising that a large proportion of our GDM subjects had hsCRP $>1 \mathrm{mg} / \mathrm{L}$. The large Diabetes Prevention Study (DPP) study revealed moderate weight loss through lifestyle intervention resulted in a reduction of hsCRP by $29 \%$ (i.e. $\approx 0.5 \mathrm{mg} / \mathrm{L}$ ) which persisted without further weight loss. Hence, lifestyle changes or behavioural therapy aiming for weight loss among post-GDM subjects will have an added benefit of lowering hsCRP levels in those with higher levels of this inflammatory marker [25]. It is acknowledged that while several interventions both pharmacologic and lifestyle modification have shown to lower hsCRP levels, the impact of the reduction on clinical outcomes remains to be convincingly established [26].

There was no significant correlation between the diagnosis of MetS and hsCRP levels. Furthermore, within the normoglycaemic subjects without Met S, more than a quarter (27.3\%) had hsCRP levels $>3 \mathrm{mg} /$ $\mathrm{ml}$. Therefore, this may suggest that MetS is insufficient to identify the complete spectrum of cardiovascular risk in post-GDM subjects and hsCRP may provide further information on residual CVD risks.

Earlier diagnosis of GDM during the ante-natal period was significantly associated with postpartum central obesity, dysglycaemia, higher BP, dyslipidaemia and MetS diagnosis. This is consistent with reports from earlier studies [18]. Family history of diabetes was associated with higher TC, TC: HDL ratios and LDL- cholesterol, which confirmed similar findings from Italy and Gambia $[27,28]$.

Correlation analysis showed higher TG levels to be associated with postpartum dysglycaemia and with every $1 \mathrm{mmol} / \mathrm{L}$ increase in TG there is a two-fold increase in the odds ratio for postpartum dysglycaemia which is similar to data collected among Korean Post-GDM women [29]. This further strengthens the associations between increased body weight, insulin resistance and postprandial glucose metabolism in the development of cardio-metabolic risks [30]; and emphasizes the need for glucose tolerance evaluation.

The current study was limited by the small sample size and confined to single-centre recruitment. Nevertheless, the results have provided evidence on the importance of detecting abnormal glucose tolerance and $\mathrm{CV}$ risk assessment in Post-GDM women within the reproductive age.

In conclusion, we demonstrated that MetS is a relevant diagnosis to detect in normoglycaemic post-GDM women. Subjects with abnormal glucose tolerance (IFG or IGT or both) had expectedly higher prevalence of MetS but a small proportion (13\%) of subjects with normoglycaemia met the diagnosis as well. Postpartum MetS screening did not predict postpartum IGT which strongly suggests the importance of OGTT in the absence of IFG to rule out glucose intolerance. Maternal age, infant birth weight and TG were independent predictors of postpartum 
Citation: Shyam S, Arshad F, Ghani RA, Wahab NA, Chinna K, et al. (2014) Metabolic Syndrome, Abnormal Glucose Tolerance and High SensitivityC-Reactive Protein among Women with a History of Gestational Diabetes Mellitus. J Diabetes Metab 5: 424 doi:10.4172/2155-6156.1000424

dysglycaemia. Dysglycaemia, earlier GDM diagnosis and family history of diabetes were associated with increased cardiovascular risks.

\section{Acknowledgements}

This project was funded by an internal research grant from the International Medical University, Kuala Lumpur (Project Code: IMU 199/2009). The authors acknowledge the assistance and support of the laboratory staff of University Kebangsaan Malaysia Medical Centre (UKMMC).

The authors acknowledge the assistance of the laboratory staff of Universiti Kebangsaan Malaysia Medical Centre (UKMMC) for their laboratory services and co-operation. This project was funded by an internal research grant from the International Medical University, Kuala Lumpur. The authors have no potentia conflict of interest to declare. The corresponding author was previously affiliated with UKMMC but had later moved to her current position during the submission of this manuscript.

\section{Location of the Study and Ethics Approvals}

The study was conducted at the Endocrinology Unit of Universiti Kebanagsaan Malaysia Medical Centre (UKMMC), Kuala Lumpur, Malaysia. The project was approved by Ethics and Research Review Committee of International Medical University, Kuala Lumpur and the Research Committee of UKMMC. The study is registered with Malaysian National Medical Research Register (NMRR) with the Research ID: 5183.

\section{References}

1. Ratner RE (2007) Prevention of type 2 diabetes in women with previous gestational diabetes. Diabetes Care 30 Suppl 2: S242-245.

2. Ko GT, Chan JC, Tsang LW, Li CY, Cockram CS (1999) Glucose intolerance and other cardiovascular risk factors in chinese women with a history of gestational diabetes mellitus. Aust N Z J Obstet Gynaecol 39: 478-483.

3. Chittleborough CR, Baldock KL, Taylor AW, Hague WM, Willson T, et al. (2010) Long-term follow-up of women with gestational diabetes mellitus: the South Australian Gestational Diabetes Mellitus Recall Register. Aust N Z J Obstet Gynaecol 50: 127-131.

4. Metzger BE, Buchanan TA, Coustan DR, de Leiva A, Dunger DB, et al. (2007) Summary and recommendations of the Fifth International WorkshopConference on Gestational Diabetes Mellitus. Diabetes Care 30 Suppl 2 S251-260.

5. Scott M Grundy, H Bryan Brewer Jr, James I Cleeman, Sidney C Smith Jr, Claude Lenfant, et al. (2004) Definition of metabolic syndrome: report of the National Heart, Lung, and Blood Institute/American Heart Association conference on scientific issues related to definition. Arterioscler Thromb Vasc Biol 24:e13-18

6. Alberti KG, Eckel RH, Grundy SM, Zimmet PZ, Cleeman JI, et al. (2009) Harmonizing the metabolic syndrome: a joint interim statement of the International Diabetes Federation Task Force on Epidemiology and Prevention; National Heart, Lung, and Blood Institute; American Heart Association; World Heart Federation; International Atherosclerosis Society; and International Association for the Study of Obesity. Circulation 120: 1640-1645.

7. Retnakaran R, Qi Y, Connelly PW, Sermer M, Zinman B, et al. (2010) Glucose intolerance in pregnancy and postpartum risk of metabolic syndrome in young women. J Clin Endocrinol Metab 95: 670-677.

8. Pepys MB1, Hirschfield GM (2003) C-reactive protein: a critical update. J Clin Invest 111: 1805-1812.

9. Libby P1, Ridker PM, Hansson GK; Leducq Transatlantic Network on Atherothrombosis (2009) Inflammation in atherosclerosis: from pathophysiology to practice. J Am Coll Cardiol 54: 2129-2138.

10. Kip KE1, Marroquin OC, Kelley DE, Johnson BD, Kelsey SF, et al. (2004) Clinical importance of obesity versus the metabolic syndrome in cardiovascular risk in women: a report from the Women's Ischemia Syndrome Evaluation (WISE) study. Circulation 109: 706-713.

11. Haffner SM (2006) The metabolic syndrome: inflammation, diabetes mellitus, and cardiovascular disease. Am J Cardiol 97: 3A-11A.

12. World Health Organization: Definition and diagnosis of diabetes mellitus and intermediate hyperglycemia: report of a WHO/IDF consultation. Geneva, World Health organization, 2006

13. American Diabetes Association. Diagnosis and Classification of Diabetes Mellitus (2007). Diabetes Care 30:S42-S47.
14. World Health Organization: WHO STEPS Surveillance In Part 3: Training and Practical Guides; Guide to Physical Measurements (Step 2) (2008). Geneva, World Health Organization.

15. Pallardo LF, Herranz L, Martin-Vaquero P, Garcia-Ingelmo T, Grande C, et al (2003) Impaired Fasting Glucose and Impaired Glucose Tolerance in Women With Prior Gestational Diabetes Are Associated With a Different Cardiovascular Profile. Diabetes Care 26:2318-2322.

16. Thomas A Pearson, George A Mensah, R Wayne Alexander, Jeffrey Anderson, Richard O Cannon III, et al. (2003) Markers of Inflammation and Cardiovascular Disease: Application to Clinical and Public Health Practice: A Statement for Healthcare Professionals from the Centers for Disease Control and Prevention and the American Heart Association. Circulation 107:499-511.

17. Ministry of Health (Malaysia): Clinical Practical Guidelines on Management of Obesity (2004). Putrajaya

18. Ben-Haroush A, Yogev Y, Hod M (2004) Epidemiology of gestational diabetes mellitus and its association with Type 2 diabetes. Diabet Med 21: 103-113.

19. Verma A, Boney CM, Tucker R, Vohr BR (2002) Insulin resistance syndrome in women with prior history of gestational diabetes mellitus. J Clin Endocrinol Metab 87: 3227-3235.

20. Shafei MN, Awang AF, Mohamad WMZW (2011) Prevalence of metabolic syndrome and its associated factors among female nurses in a teaching hospital in North-Eastern state of Malaysia. J. Public Health Epidemiol 3:394400 .

21. Wan Nazaimoon WM, MSSM Team: Metabolic Syndrome in Malaysia (MSSM). JMEMS.

22. Reinblatt SL, Morin L, Meltzer SJ (2006) The importance of a postpartum 75 $\mathrm{g}$ oral glucose tolerance test in women with gestational diabetes. J Obstet Gynaecol Can 28: 690-694.

23. Facchini FS, Hua N, Abbasi F, Reaven GM (2001) Insulin resistance as predictor of age-related diseases. J Clin Endocrinol Metab 86: 3574-3578.

24. Yajnik CS, Joglekar CV, Pandit AN, Bavdekar AR, Bapat SA, et al. (2003) Higher offspring birth weight predicts the metabolic syndrome in mothers but not fathers 8 years after delivery: the Pune Children's Study. Diabetes 52 : 2090-2096.

25. Reinhardt JA, van der Ploeg HP, Grzegrzulka R, Timperley JG (2012) Implementing lifestyle changes through phone-based motivational interviewing in rural-based women with previous gestational diabetes mellitus. Health Promot J Austr 23:5-9.

26. Backes JM, Howard PA, Moriarty PM (2004) Role of C-reactive protein in cardiovascular disease. Ann Pharmacother 38: 110-118.

27. Pannacciulli N, De Pergola G, Ciccone M, Rizzon P, Giorgino F, et al. (2003) Effect of family history of type 2 diabetes on the intima-media thickness of the common carotid artery in normal-weight, overweight, and obese glucosetolerant young adults. Diabetes Care 26: 1230-1234.

28. van der Sande MA, Walraven GE, Milligan PJ, Banya WA, Ceesay SM, et al. (2001) Family history: an opportunity for early interventions and improved control of hypertension, obesity and diabetes. Bull World Health Organ 79 : 321-328.

29. Lim S, Choi SH, Park YJ, Park KS, Lee HK, et al. (2007) Visceral fatness and insulin sensitivity in women with a previous history of gestational diabetes mellitus. Diabetes Care 30: 348-353.

30. Coutinho M, Gerstein HC, Wang Y, Yusuf S (1999) The relationship between glucose and incident cardiovascular events. A metaregression analysis of published data from 20 studies of 95,783 individuals followed for 12.4 years. Diabetes Care 22:233-240. 